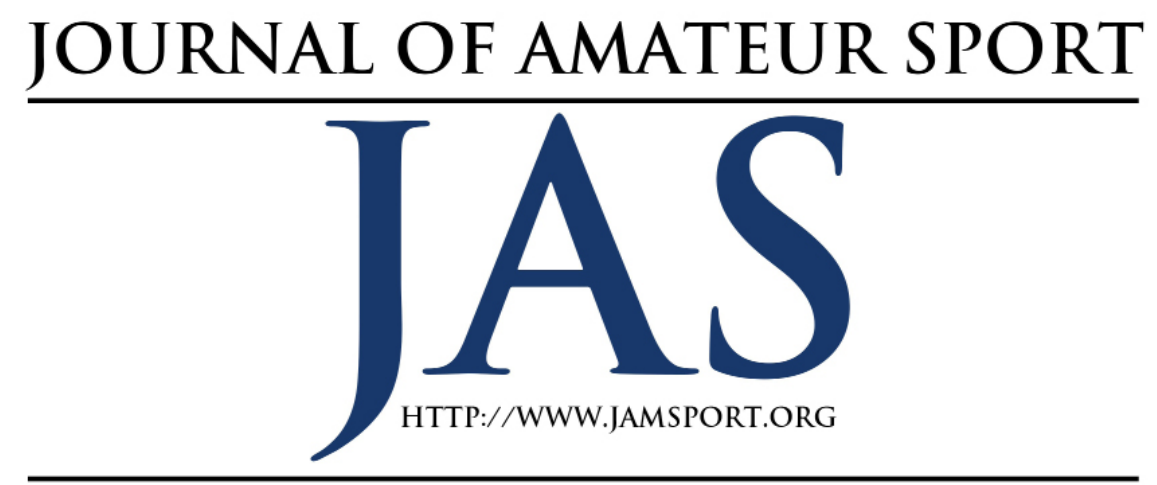

\title{
The Verbal Aggression of Spectators at Youth Baseball Games: Investigating the Impact of Competition Level, Team Identification, and Fan Dysfunction
}

\author{
Daniel L. Wann ${ }^{1} \quad$ Michelle R. Sherman ${ }^{2}$ \\ ${ }^{1}$ Murry State University \\ ${ }^{2}$ The Aspire Group
}

\begin{abstract}
Previous research had found that level of team identification was positively associated with aggression at youth sporting events (Wann, Weaver, Belva, Ladd, \& Armstrong, 2015). The current investigation was designed to extend this work by incorporating fan dysfunction into the model (i.e., fans who are confrontational and frequently complain). Spectators at either a recreational or select (i.e., travel) youth baseball game completed a survey packet assessing demographics, team identification with their favorite Major League Baseball team, identification with the youth team, fan dysfunction, and hostile and instrumental verbal aggression directed toward officials and opponents. Results indicated that, contrary to expectations, team identification was not a unique predictor of verbal aggression. Rather, fan dysfunction predicted each form of aggression, aggression toward both targets, and total aggression.
\end{abstract}

\section{1though there are a number of positive outcomes associat- \\ $\mathcal{L}$ ed with participation in youth} sports (e.g., reduced risk for suicide and improved self-confidence, see Jones, Dunn, Holt, Sullivan, \& Bloom, 2011; Taliaferro, Rienzo, Miller, Pigg, \& Dodd,
2010), research reveals that there is also an unfortunate darker side. Specifically, several recent investigations have shed light on the abusive and aggressive actions sometimes exhibited by spectators at children's sporting events. For example, Hennessy and Schwartz (2007) 
found that several personality variables predicted various forms of verbal aggression among spectators at youth baseball games, including gender, trait anger, and vengeance.

Wann, Weaver, Belva, Ladd, and Armstrong (2015) recently replicated and extended Hennessey and Schwartz (2007) by incorporating team identification into the model. Previous work had indicated that team identification (e.g., the extent to which a fan feels a psychological connection to a team, see Wann \& James, 2019) is a key predictor of sport fan aggression (Dietz-Uhler \& Lanter, 2008; Wann, 2006; Wann, Carlson, \& Schrader, 1999). In their work, Wann and his associates (2015) surveyed spectators attending youth baseball tournaments. Participants completed a measure assessing demographic items (e.g., gender), scales utilized by Hennessey and Schwartz (2007) (e.g., scales assessing levels of vengeance and anger), their level of identification with the child's team they were watching that day/evening, and a measure assessing their verbal aggression toward a number of different targets (e.g., the opposition's coach, their own child).

Wann et al. (2015) examined predictors of aggression via a series of regression analyses. Consistent with expectations and past research, the results indicated that team identification was a significant unique predictor of verbal aggression; higher levels of verbal aggression were reported by persons with higher levels of identification.
Additionally, Wann and his colleagues noted that the level of identification reported by the participants was particularly high, a finding that is particularly noteworthy given that this person variable was a significant positive predictor of verbal aggression.

\section{The Current Investigation}

Although their work was certainly a step forward in our understanding of the aggressive acts of youth sport spectators, Wann and his associates (2015) acknowledged that there is much work still to be done. One research void they noted is the lack of inclusion of fan dysfunction as a predictor of aggression. Work on fan dysfunction was generally initiated by Wakefield and Wann (2006). Noting that some highly identified fans tend to be particularly abusive and prone to violence (Gibson, Willming, \& Holdnak, 2002), Wakefield and Wann attempted to develop a method for identifying and classifying these individuals. The authors chose the term "dysfunctional" to label these fans because their actions as fans likely indicates impaired functioning with respect to sport fan socialization and social relationships and, as such, appears to be similar to other forms of social and psychological dysfunction (Bech, 1994; Sjoestroem, Eder, Malm, $\&$ Beskow, 2001). Based on their operationalization of the construct, fan dysfunction concerns the extent to which fans complain and are confrontational (Wakefield \& Wann, 2006). As a result, 
Wakefield and Wann developed a psychometrically sound instrument to assess the extent to which fans exhibit these behaviors. Then, using this scale, they investigated the manner in which the actions, attributes, and attitudes of fans differed as a function of their being categorized as high or low in dysfunction.

Participants in their research were highly identified supporters of a college football team who completed a questionnaire packet either online or at a football contest (Wakefield \& Wann, 2006). The questionnaire assessed level of fan dysfunction, demographics, and a variety of fan behaviors. The results revealed a number of important and interesting differences between the high and low dysfunction groups. With respect to demographics, those categorized as highly dysfunctional (relative to those low in dysfunction) were younger, less educated, had lower income levels, and were more likely to be male and single. In terms of fan behaviors, relative to those with low levels of dysfunction, highly dysfunctional persons were more likely to verbally abuse officials, consume alcohol while watching sport, and attend away games (where opportunities for confrontation should be readily available).

In recent years, researchers have added to our understanding of dysfunctional fans and their work does not paint of flattering picture of these persons. For example, investigators have found that highly dysfunctional fans tend to be quite assertive (Wann \& Ostrander, 2017) and they are prone to bullying behaviors (Courtney \& Wann, 2010). Additionally, as with team identification, recent work suggests that fan dysfunction is also a critical predictor of sport fan aggression (Wann \& James, 2019). For example, dysfunctional fans are more likely to view spectator aggression as appropriate (Donahue \& Wann, 2009), more likely to consider engaging in anonymous acts of spectator aggression (Wann \& Waddill, 2014), and view sport and war as similar (Wann \& Goeke, 2017).

The current investigation was designed to extend Wann et al. (2015) by including fan dysfunction as a predictor (along with team identification) of the verbal aggression of youth sport spectators. We investigated both hostile and instrumental verbal aggression directed at both officials (e.g., umpires) and opponents. Hostile aggression involves acts intended simply to harm the target while instrumental aggression involves aggression designed to lead to a specific goal (such as improved team performance; see Baron \& Richardson, 1994; Dodge \& Coie, 1987; Wann \& James, 2019). Previous work had found that spectators were more likely to direct their verbal aggression toward officials than opponents (Wann et al., 1999; Wann, Schrader, \& Carlson, 2000). As a result, we expected a similar pattern of effects among youth sport spectators. 
With respect to the impact of fan dysfunction, recent work by Wann, Waddill, Bono, Scheuchner, and Ruga (2017) was used to guide predictions. These investigators used both team identification and fan dysfunction to predict the hostile and instrumental verbal aggression of sport spectators. The results indicated that both fan dysfunction and team identification predicted total aggression (i.e., aggression collapsed across both type and target). Furthermore, team identification was a significant predictor of aggression directed at officials, aggression directed at opponents, and instrumental aggression. Fan dysfunction predicted aggression directed at officials, aggression directed at opponents, hostile aggression, and instrumental aggression. Thus, the critical difference between the impact of identification and dysfunction concerned hostile aggression as fan dysfunction was a predictor of this form of aggression while team identification was not. Based on this pattern of effects, Wann and his associates (2017) suggested that persons high in dysfunction may utilize verbal aggression to both harm others (hostile aggression) and to help their team (instrumental aggression), while persons high in identification simply act in a verbally aggressive fashion in an attempt to improve their team's chances of winning.

Given the findings presented by Wann et al. (2017), as well as work by
Wann et al (1999) and Wann et al. (2000), we expected similar results in the current research. Specifically, the following hypotheses and research questions were tested:

Hypothesis 1: It was expected that spectators would be more likely to direct their verbal aggression toward officials than opponents.

Hypothesis 2a: Team identification will be a significant unique predictor of total aggression.

Hypothesis 2b: Team identification will be a significant unique predictor of aggression directed toward officials.

Hypothesis 2c: Team identification will be a significant unique predictor of aggression directed toward opponents.

Hypothesis 2d: Team identification will be a significant unique predictor of instrumental aggression.

Hypothesis 3a: Fan dysfunction will be a significant unique predictor of total aggression.

Hypothesis 3b: Fan dysfunction will be a significant unique predictor of aggression directed toward officials.

Hypothesis 3c: Fan dysfunction will be a significant unique predictor of aggression directed toward opponents.

Hypothesis 3d: Fan dysfunction will be a significant unique predictor of instrumental aggression. 
Hypothesis 3e: Fan dysfunction will be a significant unique predictor of hostile aggression.

Research Question 1: Do spectators at youth sporting events have higher levels of identification with their favorite Major League Baseball team or the youth baseball team they are watching?

\section{Method}

\section{Participants}

The original sample contained 129 spectators attending a youth baseball game. Three individuals failed to complete the entire survey and, thus, were removed from the sample. Therefore, the final sample contained 126 persons (43 males, 83 females) with an average age of 42.41 years $(S D=$ 12.51 ; range $=18$ to 77 ). In terms of competition level, 65 of the participants were attending a recreational league game, while 61 were watching a select (i.e., travel) league contest. With respect to their relationship with the child they were watching, 89 (71\%) were watching their own child, $23(18 \%)$ were watching their grandchild, and 14 (11.1\%) selected "other." The average age of the age of the children being watched was 10.70 years $(S D=1.58$; range $=7$ to 15$)$. Most of the children were between the ages of 10 and $12(71.5 \%)$.

\section{Procedure}

Potential participants were approached after a youth baseball game at one of two locations in the mid- south (approval from the institution's IRB and the baseball leagues/facilities was acquired prior to initiating this research). The games were either tournament or regular season contests for either a recreational league or travel teams. To acquire the convenience sample, researchers approached potential participants at several different fields in an attempt to get a wider range of player ages. Only persons appearing to be older than 18 were approached. No other qualifications for potential participants were utilized. Those agreeing to participate (refusal rate was less than $20 \%$ ) were given a consent letter providing general instructions for the study. Specifically, they were informed that the study was an investigation of spectator behaviors at youth sporting events and that the questionnaire packet contained items assessing demographics, personality traits, interest in their child's team, and various fan behaviors. After reading the cover letter and providing their consent, participants were handed a clipboard containing the questionnaire protocol and a pencil. They were instructed to take their time and complete each item, not to identify themselves in any way on the questionnaire so as to maintain anonymity, and that a research assistant would return shortly to collect the packet. When the assistant returned, he or she retrieved the packet and pencil, thanked the participant for his or her participation, and handed the respondent a debriefing statement describing the 
nature and hypotheses of the research. This form contained information on contacting the lead author should the participant have questions or desire a copy of the final report. Completion of the packet required approximately 15 minutes.

\section{Materials}

The questionnaire packet contained five sections, the first of which assessed demographics. Specifically, respondents indicated their age, gender, age of the child they were watching, their relationship with the child (participants were to circle "son/daughter, grandson/ granddaughter or other"), and whether the child played select (i.e., travel, elite) baseball or recreational baseball.

For the next two sections, participants completed two versions of the sevenitem Sport Spectator Identification Scale (SSIS; Wann \& Branscombe, 1993). The SSIS is a tool for assessing team identification that has been successfully used in numerous studies and has demonstrated reliability and validity in past work (see Wann \& James, 2019). First, subjects listed their favorite Major League Baseball (MLB) team and then completed the SSIS for that specific team. Next, they were instructed to target the child's team when completing the second version of the SSIS.

Response options on both forms of the Likert-scale SSIS ranged from 1 (low identification) to 8 (bigh identification). Thus, higher numbers represented greater levels of team identification for the MLB and youth teams.

The fourth section contained the Dysfunctional Fandom Questionnaire (DFQ; Wakefield \& Wann, 2006). The DFQ contains five Likert-scale items assessing dysfunction as a fan (e.g., confrontation, complaining). Response options to the DFQ ranged from 1 (low dysfunction) to 10 (bigh dysfunction). Thus, higher numbers reflected greater levels of dysfunction as a fan. Participants were asked to target the child's baseball team when completing the DFQ.

The last portion of the questionnaire packet contained the eight-item Hostile and Instrumental Aggression in Sport Questionnaire (HIASQ; Wann et al., 1999; Wann et al., 2000). The HIASQ is a Likert-scale measure assessing the extent to which spectators act in a verbally aggressive manner toward opposing players and officials for hostile and instrumental reasons. Participants were asked to indicate their responses based on their actions at the game they had just witnessed (thus, the HIASQ was a state measure of aggression). Scores ranged from 1 (not at all) to 8 (a great deal). As a result, higher scores reflected greater levels of hostile and instrumental verbal aggression. A sample item assessing hostile aggression directed toward the officials read: "To what extent did you yell at the officials because you were mad at him/her and wanted to hurt him/her in some way?" A sample item assessing instrumental 
aggression directed toward the opposing team read: "To what extent did you yell at the opposing players and coaches because you believed it would help your team win?" In addition to utilizing the HIASQ to acquire a Total Aggression (TA) score, specific items were summed to acquire measures of Hostile Aggression toward Officials (HAOFF; 2 items), Instrumental Aggression toward Officials (IAOFF; 2 items), Hostile Aggression toward Opponents (HAOPPO; 2 items), Instrumental Aggression toward Opponents (IAOPPO; 2 items), Total Instrumental Aggression (IA; instrumental aggression across target; 4 items), Total Hostile Aggression (HA; hostile aggression across target; 4 items), Total Aggression Directed at Officials (OFF; officials as targets across aggression type; 4 items), and Total Aggression Directed at Opponents (OPPO; opponents as targets across aggression type; 4 items).

\section{Results}

\section{Preliminary Analyses}

Items on the DFQ, two forms of the SSIS, HIASQ subscales, and HIASQ total scale (TA) were summed to form indices for each. Means, standard deviations, and Cronbach's alphas appear in Table 1 (all had acceptable reliability scores). Gender differences were examined via a Multivariate Analysis of Variance (MANOVA) in which

Table 1

Means, Standard Deviations, and Cronbach Reliability Alphas for the Measures.

\begin{tabular}{lcrc}
\hline Measure & Mean & SD & Alpha \\
\hline Fan Dysfunction $^{\mathrm{a}}$ & 12.34 & 8.35 & .803 \\
Team Identification with MLB Team $^{\mathrm{b}}$ & 35.29 & 13.18 & .922 \\
Team Identification with Youth Baseball Team $^{\mathrm{b}}$ & 40.79 & 9.62 & .804 \\
Hostile Aggression toward Officials $^{\mathrm{c}}$ & 3.24 & 2.39 & .676 \\
Instrumental Aggression toward Officials $^{\mathrm{c}}$ & 3.02 & 2.59 & .945 \\
Hostile Aggression toward Opponents $^{\mathrm{c}}$ & 2.74 & 2.21 & .913 \\
Instrumental Aggression toward Opponents $^{\mathrm{c}}$ & 2.52 & 1.71 & .962 \\
Instrumental Aggression $^{\mathrm{d}}$ & 5.55 & 3.95 & .900 \\
Hostile Aggression $^{\mathrm{d}}$ & 5.98 & 4.32 & .874 \\
Aggression Toward Officials $^{\mathrm{d}}$ & 6.26 & 4.56 & .865 \\
Aggression Toward Opponents $^{\mathrm{d}}$ & 5.26 & 3.73 & .932 \\
Total Aggression $^{\mathrm{e}}$ & 11.52 & 7.80 & .927 \\
\hline
\end{tabular}

Notes: ${ }^{\mathrm{a}}$ potential range $=5$ to $50 ;{ }^{\mathrm{b}}$ potential range $=7$ to $56 ;{ }^{\mathrm{c}}$ potential range $=2$ to $16 ;{ }^{\mathrm{d}}$ potential range $=4$ to $32 ;{ }^{\mathrm{e}}$ potential range $=8$ to 64 .

Journal of Amateur Sport Volume Five, Issue One Wann and Sherman., 2019102 
identification for the favorite MLB team, identification for the youth team, fan dysfunction, and total aggression score were utilized as the dependent measures. This examination failed to reveal a significant multivariate gender effect, Wilks' Lambda $F(4,102)=1.64, p=$ .17 (the lower $d f$ was a function of only 107 participants listing a favorite MLB team). Consequently, all subsequent analyses were collapsed across gender. In addition, correlations were computed between the child's age and each measure of aggression. Consistent with past research (Wann et al., 2015), child age was not significantly related to total verbal aggression, $r=-.14, p=.12$. Thus, all subsequent computations were conducted across child age.

\section{Examination of Hypotheses and Research Question}

\section{Hostile and instrumental} aggression directed toward officials and opponents. Next, a MANOVA was computed on the HAOFF, IAOFF, HAOPP, and IAOPP subscales. A significant target effect confirmed Hypothesis 1, Wilks' Lambda F(1, $125)=14.72, p<.001$. As predicted, the spectators at the youth baseball game were more likely to direct their aggression toward officials $(M=6.26$, $S D=4.56)$ than toward the opposition $(M=5.26, S D=3.73)$. The aggression type effect was not statistically significant, Wilks' Lambda $F(1,125)$ $=3.05, p=.08$, although there was a tendency for spectators to be more likely to exhibit hostile aggression $(M=5.98$, $S D=4.32)$ than instrumental aggression $(M=5.55, S D=3.95)$. The MANOVA also failed to indicate an interaction between aggression type and aggression target, Wilks' Lambda $F(1,125)=0.00, p$ $=1.00$.

Impact of team identification, fan dysfunction, and competition level. The final series of analyses investigated predictors of hostile and instrumental aggression targeting officials and opponents (correlations between the predictor variables and the dependent variables appear in Table 2, a complete correlation matrix is available from the first author upon request). Hypotheses $2 \mathrm{a}$ through $2 \mathrm{~d}$ (i.e., hypotheses involving team identification) and Hypotheses $3 \mathrm{a}$ through $3 \mathrm{e}$ (i.e., hypotheses involving fan dysfunction) were tested via a series of nine regression analyses in which competition level, identification with the youth baseball team, and fan dysfunction served as predictor variables and the various assessments of verbal aggression (e.g., hostile aggression, aggression directed toward officials) were utilized as dependent variables. Table 3 depicts the results of the first five regressions which targeted total aggression, hostile aggression, instrumental aggression, aggression toward officials, and aggression toward opponents. As shown in the table, identification failed to account for a significant proportion of unique variance. Thus Hypotheses 2a, 2b, 2c, and 2d were not supported. However, an equally 
Table 2

Correlations between the predictor variables and the indices of aggression.

Predictor Variables

\begin{tabular}{lccc}
\hline & $\begin{array}{c}\text { Competition } \\
\text { Level }\end{array}$ & $\begin{array}{c}\text { Fan } \\
\text { Dysfunction }\end{array}$ & $\begin{array}{c}\text { Identification } \\
\text { with } \\
\text { Youth Team }\end{array}$ \\
\hline Hostile Aggression toward Officials & .15 & $.67^{* *}$ & $.24^{* *}$ \\
Instrumental Aggression toward Officials & $.18^{*}$ & $.58^{* *}$ & $.26^{* *}$ \\
Hostile Aggression toward Opponents & .09 & $.58^{* *}$ & $.18^{*}$ \\
Instrumental Aggression toward Opponents & .04 & $.46^{* *}$ & .11 \\
Instrumental Aggression & .13 & $.58^{* *}$ & $.22^{*}$ \\
Hostile Aggression & .13 & $.67^{* *}$ & $.22^{*}$ \\
Aggression toward Officials & $.18^{*}$ & $.68^{* *}$ & $.27^{* *}$ \\
Aggression toward Opponents & .07 & $.56^{* *}$ & .16 \\
Total Aggression & .14 & $.67^{* *}$ & $.23^{* *}$ \\
\hline
\end{tabular}

Notes: $*=p<.05 ; * *=p<.01 .{ }^{1}$ Coded as $1=$ recreational; $2=$ select $/$ travel.

consistent pattern was found for fan dysfunction, as this variable accounted for a significant proportion of unique variance in each instance. Therefore, Hypotheses 3a, 3b, 3c, 3d, and 3e were each supported. Competition level failed to be a significant predictor in any of these five analyses. Thus, taken together, these results suggest that, for spectators at youth baseball games, level of fan dysfunction is positively associated with amount of total verbal aggression, hostile verbal aggression, instrumental verbal aggression, verbal aggression directed at officials, and verbal aggression directed at opponents. Additionally, team identification and level of competition are not significantly related to these forms of verbal aggression.

The next four regressions examined the four combinations of aggression type and aggression target (see Table 4). The patterns mirrored those of the previous analyses. That is, for all analyses, identification was not a significant predictor while fan dysfunction was (thus, Hypotheses 2a through 2d were again rejected, while Hypotheses 3 a through $3 e$ were supported). Furthermore, competition level was not a significant predictor, a pattern also consistent with the previous series of regressions.

\section{MLB and youth team} identification. The final series of 


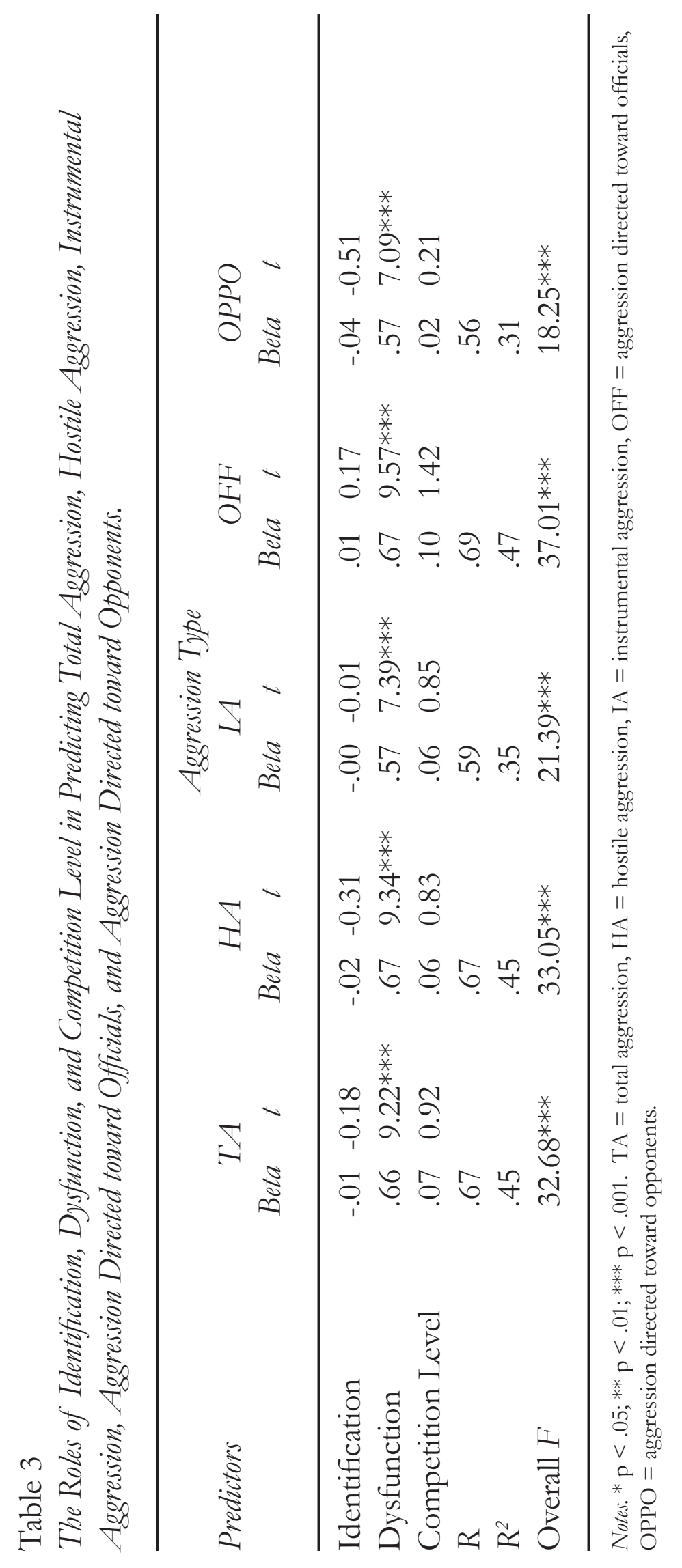

Journal of Amateur Sport Volume Five, Issue One Wann and Sherman., 2019 
Table 4

The Roles of Identification, Dysfunction, and Competition Level in Predicting Hostile Aggression toward Officials, Instrumental Aggression toward Officials, Hostile Aggression toward Opponents, and Instrumental Aggression toward Opponents.

\begin{tabular}{|c|c|c|c|c|c|c|c|c|}
\hline \multirow{3}{*}{ Predictors } & \multicolumn{8}{|c|}{ Aggression Type } \\
\hline & \multicolumn{2}{|c|}{$H A O F F$} & \multicolumn{2}{|c|}{ IAOFF } & \multicolumn{2}{|c|}{ HAOPPO } & \multicolumn{2}{|c|}{ LAOPPO } \\
\hline & Beta & $t$ & Beta & $t$ & Beta & $t$ & Beta & $t$ \\
\hline Identification & -.01 & -0.16 & .03 & 0.40 & -.03 & -0.40 & -.05 & -0.56 \\
\hline Dysfunction & .67 & $9.43^{* * *}$ & .56 & $7.21 * * *$ & .58 & $7.42 * * *$ & .41 & $5.64 * * *$ \\
\hline Competition Level & .08 & 1.11 & .10 & 1.31 & .03 & 0.39 & .00 & 0.03 \\
\hline $\mathrm{R}$ & \multicolumn{2}{|l|}{.68} & \multicolumn{2}{|l|}{.59} & \multicolumn{2}{|l|}{.58} & \multicolumn{2}{|l|}{.47} \\
\hline$R^{2}$ & \multicolumn{2}{|l|}{.46} & \multicolumn{2}{|l|}{.35} & \multicolumn{2}{|l|}{.33} & \multicolumn{2}{|l|}{.22} \\
\hline Overall $F$ & \multicolumn{2}{|c|}{$34.51 * * *$} & \multicolumn{2}{|c|}{$22.07 * * *$} & \multicolumn{2}{|c|}{$20.35^{* * *}$} & \multicolumn{2}{|c|}{$11.29 * * *$} \\
\hline
\end{tabular}

Notes. ${ }^{*} \mathrm{p}<.05 ;{ }^{* *} \mathrm{p}<.01 ; * * * \mathrm{p}<.001$. HAOFF $=$ hostile aggression toward officials, IAOFF $=$ instrumental aggression toward officials, HAOPPO = hostile aggression toward opponents, IAOPPO = instrumental aggression toward opponents.

analyses involved a comparison

of participants' identification with their favorite MLB team and their identification with the youth baseball team. A paired samples t-test conducted on persons with a favorite MLB team $(n=107)$ revealed a significant effect, $t(106)=5.61, p<.001$. Specifically, participants reported a greater level of identification for the youth team $(M=41.88 ; S D=9.16)$ than for the MLB team $(M=35.29$; $S D=13.18)$. We then examined the identification scores separately for persons viewing recreational and select games. The two paired samples t-tests revealed higher scores for the youth team regardless of the competition level being viewed (participants viewing a recreational contest: youth team identification $M=39.00 ; S D=7.86$, MLB team identification $M=31.77$; $\mathrm{SD}=12.12$, $t(46)=3.77, p=.001$; participants viewing a select contest: youth team identification $M=44.13$; $S D=9.52$, MLB team identification $M=38.05$; $S D$ $=13.41, t(59)=4.20, p<.001)$. Finally, in an examination of competition level, a pair of independent samples t-tests indicated that persons watching a select contest had higher levels of identification than those watching a recreational contest, a pattern that held for both their favorite MLB team and the youth team $($ MLB identification $t(105)=2.51, p=$ .014 ; youth identification $t(105)=2.98, p$ $=.004)$. 


\section{Discussion}

The current investigation extended past work on the aggressive actions of spectators at youth sporting events. Prior research has provided an understanding of the personality traits associated with aggression at these contests, including vengeance (Hennessy \& Schwartz, 2007) and team identification (Wann et al., 2015). However, by incorporating fan dysfunction as a predictor, the current work was able to add to our understanding of those persons prone to these actions. The results presented above indicate that the inclusion of this variable is critical, as dysfunction was found to play a central role in the verbal aggression exhibited by fans at youth sport contests.

The regression analyses painted a very consistent picture, as team identification failed to predict any form of aggression while fan dysfunction was a significant predictor in each instance. This suggests that to best understand the verbal aggression of youth sport spectators, individuals may need to focus their attention on dysfunction rather than (or in addition to) team identification. The lack of significance for identification is surprising as a number of studies have found this to be a key factor of sport fan aggression (Wann \& James, 2019), including violence among fans at children's sporting events (Wann et al., 2015). Given this, it will be important to replicate the current results in future endeavors to confirm the generalizability of the findings presented here.
The data and results detailed above clearly indicate that individuals associated with youth sport (e.g., league administrators, officials, parks and recreation departments) should most certainly include fan dysfunction in their models of spectator anti-social behavior. Persons responsible for youth sporting events have an obligation to provide a safe and supportive environment, one free of verbal abuse. By understanding the types on individuals most likely to act in a verbally aggressive manner (i.e., those high in fan dysfunction), league officials can develop strategies for identifying dysfunctional fans and lowering their dysfunction, initiate more effective strategies for reducing the amount of violence, and implement policies for dealing with those persons who engage in such acts.

An examination of the target of aggression replicated past work (Wann et al., 1999; Wann et al., 2000), as officials were more likely than opponents to incur the verbal wrath of the participants. This pattern of effects has now been found with multiple sports (i.e., baseball and basketball) and at multiple levels of competition (i.e., youth sports and collegiate sports), and therefore, appears to be a robust finding. However, it is important to note that officials at youth sporting events (e.g., baseball umpires) are rarely professionals. Rather, many are unpaid (or poorly paid) volunteers and they often are quite young themselves. Given this, the fact that any amount 
of verbal aggression is directed toward these persons is unfortunate. Sport officiating can be quite stressful (Anshel \& Weinberg, 1995; Kaissidis \& Anshel, 1993; Weinberg \& Richardson, 1990), and the verbally assaultive statements of spectators at youth contests likely add undue anxiety to the situation.

We also compared participants' identification with their favorite Major League Baseball team with their identification with the child's team. This comparison was undertaken based on results presented by Wann et al. (2015) indicating that persons watching youth sport had unexpectedly high levels of identification for the youth team. Our findings corroborate the high levels of youth team identification reported by Wann and his associates. In fact, our sample had higher levels of identification with the youth team than for their favorite MLB team, a pattern of effects that held for both supporters of a recreational team and those following a more competitive team. At first glance, the high level of youth team identification may seem problematic, given that previous work had implicated identification as a key predictor in aggression among youth sport fans (Wann et al., 2015). However, the current data suggest that the high level of psychological connection some adults feel for a youth team may not be cause for apprehension because, as noted above, identification was not found to be a significant predictor of verbal aggression. Although past authors have expressed concern over the strong identification adults feel with youth athletes and teams (Wann, 2001, 2006), the current findings suggest that individuals should be more worried about youth sport spectators with high levels of fan dysfunction.

It is also interesting that level of competition (i.e., recreational versus select/travel team games) was not a significant factor in youth spectator aggression. Such a pattern may be surprising. That is, it seems that higher levels of verbal aggression may have been found among those viewing the more competitive games (i.e., the select/ travel team contests). Likewise, one may have expected higher levels of aggression in contests played by older children, another pattern that was not found here (nor elsewhere, see Wann et al., 2015).

Furthermore, it warrants mention that, across the entire sample, the frequency of verbal aggression was quite low. Indeed, the total verbal aggression score of approximately 11.5 on a scale ranging from 8 to 64 seems to be a bit of welcome news. However, given that the total aggression score standard deviation was almost 8 , it is clear that, although the vast majority of spectators were well mannered with respect to verbal aggression, there were a handful on persons with problematic levels of these actions. Anyone who has attended a youth sporting event can attest that it only takes one "rotten apple" to spoil it for everyone. That is, if only one spectator is verbally abusing the players 
and/or officials, then there is still cause

for concern. It is inappropriate to use the low overall verbal aggression score to conclude that there really is not a problem. To the contrary, we would argue that any instance of such behavior at youth sporting events is highly problematic and worthy of the attention of researchers and league officials alike.

\section{Limitations and Suggestions for Future Research}

A number of limitations to the current work and suggestions for future endeavors warrant mention. First, it is important to note that the data gathering in the current study were self-report in nature. Thus, one cannot rule out the possibility that concerns over social desirability might have impacted the participants' responses in some instances. If this were indeed the case, the results presented above actually underreport the level of dysfunction and verbal aggression at youth baseball games.

Additionally, it warrants mention that the aggression instrument used in the current study assessed state aggression rather than trait (i.e., dispositional) aggression. Thus, the generalizability of the results is limited to the participants' current levels of aggression. Future research should expand on this current study by investigating the relationship between trait aggression and verbally aggressive outbursts at youth sporting events. Researchers have examined the link between trait aggression and support for professional and college teams
(Dimmock \& Grove, 2005; Koss \& Gaines, 1993; Wann, Peterson, Cothran, \& Dykes, 1999), generally finding that fandom is unrelated to trait aggression. However, work specifically examining supporters a youth sporting events appears to be lacking. Thus, efforts should attempt to fill this research void.

Future work may want to focus on different operational definitions of "game competiveness" (e.g., junior varsity versus varsity games, regular season versus post-season games) to further our understanding of the impact of this variable on the verbal aggression of youth sport spectators. Additionally, subsequent work may want to further investigate the relationships among age of the youth athletes, fan dysfunction, and level of aggressiveness. For instance, it may be that as the child athletes get older, their potential as athletes becomes more clearly defined. As a result, spectators may report lower levels of dysfunction and/or aggression know thing the child has reached his or her potential as an athlete. However, it could also be the case that as the child athlete grows older, the parents (and others) are required to make greater and greater investments into the child's athletic endeavors. The cognitive dissonance activated by such efforts may lead parents of older children to be more likely to be dysfunctional and/or verbally aggressive. Clearly, more work is needed in this area to determine the pattern such effects would take. 


\section{Conclusion}

The primary purpose of this investigation was to examine potential predictors of youth sport spectators' hostile and instrumental verbalizations. Specifically, we examined the extent to which team identification (a fan's psychological connection to a team) and fan dysfunction (a fan's tendency to be confrontational and complain) predicted the fans' vocalized aggression. As expected, fan dysfunction was found to be a significant predictor of aggression, including hostile and instrumental aggression, aggression targeting opponents and officials, and total verbal aggression. However, contrary to expectations, team identification did not account for a significant proportion of unique variance. Persons involved in youth sport (e.g., coaches, administrators) should be mindful of the relationships found in the current work and attempt to use this information to develop strategies designed to identify dysfunctional fans, lower their level of dysfunction, and thus decrease the amount of verbal aggression found at youth sporting events.

\section{References}

Anshel, M. H., \& Weinberg, R. S. (1995).

Sources of acute stress in American and Australian basketball referees. Journal of Applied Sport Psychology, 7, 11-22.

Baron, R. A., \& Richardson, D. R. (1994). Human aggression (2nd ed.). New York: Plenum.
Bech, P. (1994). Measurement by observations of aggressive behavior and activities in clinical situations. Criminal Behavior and Mental health, 4, 290-302.

Courtney, J. J., \& Wann, D. L. (2010). The relationship between sport fan dysfunction and bullying behaviors. North American Journal of Psychology, 12, 191-198.

Dietz-Uhler, B., \& Lanter, J. R. (2008). The consequences of sports fan identification. In L. W. Hugenberg, P. M. Haridakis, \& A. C. Earnheardt (Eds.), Sports mania: Essays on fandom and the media in the 21st century (pp. 103-113). Jefferson, NC: McFarland. Dimmock, J. A., \& Grove, J. R. (2005). Relationship of fan identification to determinants of aggression. Journal of Applied Sport Psychology, 17, 37-47.

Dodge, K. A., \& Coie, J. D. (1987). Social information processing factors in reactive and proactive aggression in children's peer groups. Journal of Personality and Social Psychology, 53, 1146-1158.

Donahue, T., \& Wann, D. L. (2009). Perceptions of the appropriateness of sport fan physical and verbal aggression: Potential influences of team identification and fan dysfunction. North American Journal of Psychology, 11, 419-428.

Gibson, H., Willming, C., \& Holdnak, A. (2002). "We're Gators...not just Gator fans": Serious leisure and University of Florida football. Journal of Leisure Research, 34, 397-425. 
Hennessy, D. A., \& Schwartz, S. (2007). Personal predictors of spectator aggression at little league baseball games. Violence and Victims, 22, 205215.

Jones, M. I., Dunn, J. G. H., Holt, N. L., Sullivan, P. J., \& Bloom, G. A. (2011). Exploring the '5Cs' of positive youth development in sport. Journal of Sport Behavior, 34, 250-267.

Kaissidis, A. N., \& Anshel, M. H. (1993). Sources and intensity of acute stress in adolescent and adult Australian basketball referees: A preliminary study. The Australian Journal of Science and Medicine in Sport, 25, 97-103.

Koss, M. P., \& Gaines, J. A. (1993). The prediction of sexual aggression by alcohol use, athletic participation, and fraternity affiliation. Journal of Interpersonal Violence, 8, 94-108.

Sjoestroem, N., Eder, D. N., Malm, U., \& Beskow, J. (2001). Violence and its prediction at a psychiatric hospital. European Psychiatry, 16, 459-465.

Taliaferro, L. A., Rienzo, B. A., Miller, M. D., Pigg, R. M., \& Dodd, V. J. (2010). Potential mediating pathways through which sports participation relates to reduced risk of suicidal ideation. Research Quarterly for Exercise and Sport, 81, 328-339.

Wakefield, K. L., \& Wann, D. L. (2006). An examination of dysfunctional sport fans: Method of classification and relationships with problem behaviors. Journal of Leisure Research, 38, 168-186.
Wann, D. L. (2001, June). Encouraging positive adult behavior at youth sporting events: Changing to a culture of FUN. Invited address presented at the National Alliance for Youth Sport Summit, Chicago.

Wann, D. L. (2006). The causes and consequences of sport team identification. In A. A. Raney \& J. Bryant (Eds.,) Handbook of sports and media (pp. 331-352). Mahwah, NJ: Erlbaum.

Wann, D. L., \& Branscombe, N. R. (1993). Sports fans: Measuring degree of identification with the team. International Journal of Sport Psychology, 24, 1-17.

Wann, D. L., Carlson, J. D., \& Schrader, M. P. (1999). The impact of team identification on the hostile and instrumental verbal aggression of sport spectators. Journal of Social Behavior and Personality, 14, 279-286.

Wann, D. L., \& Goeke, M. E. (2017). Relationships among dysfunctional fandom, sport fandom, team identification and perceptions of sport and war terminology. Journal of Sport Behavior, 40, 231-243.

Wann, D. L., \& James, J. D. (2019). Sport fans: The psychology and social impact of fandom. New York: Routledge Press.

Wann, D. L., \& Ostrander, A. (2017). The relationship between dysfunctional sport fandom and assertiveness. Contemporary Athletics, 11, 189-197. Wann, D. L., Peterson, R. R., Cothran, C., \& Dykes, M. (1999). Sport fan aggression and anonymity: The 
importance of team identification. Social Behavior and Personality: An International Journal, 27, 597-602. Wann, D. L., Schrader, M. P., \& Carlson, J. D. (2000). The verbal aggression of sport spectators: A comparison of hostile and instrumental motives. International Sports Journal, 4, 56-63. Wann, D. L., \& Waddill, P. J. (2014). Predicting sport fans' willingness to consider anonymous acts of aggression: Importance of team identification and fan dysfunction. In C. Mohiyeddini (Ed.), Contemporary topics and trends in the psychology of sports (pp. 139-151). Hauppauge NY: Nova. Wann, D. L., Waddill, P. J., Bono, D., Scheuchner, H., \& Ruga, K. (2017).
Sport spectator verbal aggression: The impact of team identification and fan dysfunction on fans' abuse of opponents and officials. Journal of Sport Behavior, 40, 423-443.

Wann, D. L., Weaver, S., Belva, B., Ladd, S., \& Armstrong, S. (2015). Investigating the impact of team identification on the willingness to commit verbal and physical aggression by youth baseball spectators. Journal of Amateur Sport, 1(1), 1-28.

Weinberg, R. S., \& Richardson, P. A. (1990). Psychology of officiating. Champaign, IL: Human Kinetics. 